Check for updates

Cite this: RSC Adv., 2019, 9, 19180

Received 20th March 2019

Accepted 24th May 2019

DOI: $10.1039 / c 9 r a 02171 j$

rsc.li/rsc-advances

\section{A wearable fiber-shaped supercapacitor based on a poly(lactic acid) filament and high loading polypyrrole $\uparrow$}

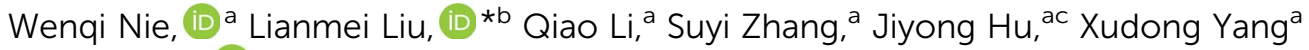 \\ and Xin Ding (D) *a
}

\begin{abstract}
There is a growing interest in fiber-shaped supercapacitors, which are likely to meet the demands of wearable electronics. However, the loading of active material is so small that the energy density of fiber supercapacitors is low. In this research, a graphene oxide/poly(pyrrole) (GO/PPy) hybrid was applied as the active material and a novel method to accomplish a high loading of the active material on poly(lactic acid) (PLA) filaments is proposed. Iron ions, as positive ions, are intercalated into GO sheets to form complexes which can be absorbed on the surface of the PLA. Furthermore, iron ions can be used as initiators to initiate pyrrole polymerization. Using complexes in which iron ions are intercalated into GO, instead of pure GO, then coated onto PLA and then polymerized using pyrrole, this method could effectively increase the loading of PPy. As a result, the active material loading is $0.121 \mathrm{mg} \mathrm{cm}^{-1}$, and the weight gain rate even reached $72.4 \%$. A high areal specific capacitance of $158.8 \mathrm{mF} \mathrm{cm}^{-2}$ and energy density of $3.5 \mu \mathrm{W} \mathrm{h} \mathrm{cm}{ }^{-2}$ are achieved using the proposed fiber-shaped supercapacitor. Meanwhile, it shows great potential for textile shaped electronics because of its fiber format.
\end{abstract}

\section{Introduction}

Wearable energy storage devices have recently become of great interest because of their portability, flexibility and wearability. ${ }^{\mathbf{1 - 5}}$ Compared with lithium ion batteries, supercapacitors are considered as the most promising type of energy source because of their advantages of high power density, fast chargedischarge capability, long cycle life and safety. ${ }^{\mathbf{1 , 6}}$ Traditional planar supercapacitors are bulky, rigid, and difficult to be integrated into systems of various configurations. In contrast, fiber-shaped supercapacitors are lightweight, flexible and easy to shape into textiles. ${ }^{7-10}$ Therefore, much effort has been devoted to developing fiber-shaped supercapacitors. ${ }^{\mathbf{1 1}}$ However, one of the major problems with fiber-shaped supercapacitors is that the active materials cannot be coated on to fiber substrates in great amounts, and the low mass loading of active materials limits the improvement of the device performance. ${ }^{\mathbf{1 2 - 1 5}}$

Usually, there are two methods to prepare fiber-shaped supercapacitors. One is a spinning method, which can achieve

${ }^{a}$ Key Laboratory of Textile Science and Technology, Ministry of Education of China, Donghua University, Shanghai 201620,China.E-mail: xding@dhu.edu.cn

${ }^{b}$ College of Materials and Textile Engineering, Jiaxing University, Jiaxing, Zhejiang 314001, China.E-mail: 1122038@mail.dhu.edu.cn

${ }^{c}$ Key Laboratory of High Performance Fibers and Products, Ministry of Education, Donghua University, Shanghai, 201620, China

$\dagger$ Electronic supplementary information (ESI) available. See DOI: $10.1039 / \mathrm{c} 9 \mathrm{ra} 02171 \mathrm{j}$ a high performance for energy-storage fibers. ${ }^{16,17}$ But the tensile strength of these fibers is much lower than the requirements for the subsequent textile processing. The other is coating the active materials onto the traditional textile fiber, (e.g., cotton or chemical filaments), which have been proved to be an effective method to obtain fiber-shaped supercapacitors by many researchers. ${ }^{18,19}$ Using this method enables the original tensile strength of the textile fibers to be kept, whereas the energy storage is relatively low. To improve capacitance, combining two active materials (e.g., carbonaceous materials and conducting polymer materials ${ }^{\mathbf{1 3}, \mathbf{1 8}}$ ) as a composite is an effective method. As is known, the molecular structure of graphene oxide (GO) has a lot of functional groups, including carbon $\mathrm{sp}^{2}(\mathrm{C}=$ $\mathrm{C})$, carbonyl $(\mathrm{C}=\mathrm{O})$, and carboxylates $(\mathrm{O}-\mathrm{C}=\mathrm{O})$. Therefore, it is easily coated on fiber [such as cotton, poly(lactic acid) (PLA), poly(imide), and so on] using chemical or hydrogen bonding. Meanwhile, poly(pyrrole) (PPy), is composed of aromatic rings with carbon $(\mathrm{C})$, nitrogen $(\mathrm{N})$ elements and also has carbon $\mathrm{sp}^{2}$ $(\mathrm{C}=\mathrm{C})$. So, the $\pi-\pi$ interactions and hydrogen bonding between the GO sheets and PPy can play a significantly role in the formation of GO/PPy nanocomposites. Therefore, they are usually applied to fiber-shaped supercapacitors. ${ }^{20,21}$

Using GO/PPy as the active material for the preparation of fiber supercapacitors, some researchers have proved its feasibility. Xu et al. ${ }^{20}$ coated GO on cotton and then compositing it with PPy on the substance to prepare a reduced graphene oxide (RGO)/PPy/cotton supercapacitor. The capacitance of the complex electrode is superior to that of an $\mathrm{RGO} /$ cotton 
electrode. Lyu et al. $^{22}$ also reported an RGO/PPy/cellulose paper supercapacitor, whose energy density could reach $0.28 \mathrm{~mW} \mathrm{~h}$ $\mathrm{cm}^{-3}$. Although a lot of work has been done on GO/PPy coated on fibers, the fiber energy density is still low. As far as is known, it has been reported that the capacitance depends on the PPy mass loading, and a high mass loading can provide high performance. ${ }^{23}$ So, the main reason for the low energy density of a fiber supercapacitor is the energy of the substance coated on the fiber is less. Generally, PPy can be obtained using chemical polymerization. ${ }^{24}$ In the process of chemical polymerization, ferric chloride $\left(\mathrm{FeCl}_{3}\right)$ is often used as the initiator. The polymerization process agrees with the kinetics given by Bjorklund. ${ }^{25}$ The pyrrole gets positive charges when oxidized by $\mathrm{FeCl}_{3}$. The charged pyrrole has a preference for adhering onto the surface of the object in solution, and then the PPy long chain macromolecules are formed when more positively charged pyrrole molecules contact. So, the PPy can be randomly grown in the fiber surface when the fiber is put into the pyrrole solution. However, it is difficult for PPy to grow evenly onto the fiber, because PPy is not uniform and the mass is low. In some cases, a GO adsorption layer on the fiber substrates prior to the PPy coating is beneficial to the electrochemical performance. ${ }^{17}$ However, the mass loading of PPy is still less. Therefore, it is necessary to find a way to increase the mass loading of PPy on the GO-coated fiber substrates.

In this research, GO was modified by introducing iron ions. The GO is an electronegative material, so using iron ions (positive charge) can be used to achieve modified GO to form a stable mixture. The mixture was first coated onto a PLA filament, as the substrate material, which can keep its tensile strength after coating with active materials. This step makes the mixed active material $\left(\mathrm{FeCl}_{3}\right.$ and $\left.\mathrm{GO}\right)$ coated on the surface of PLA. After that, the modified PLA was put into pyrrole solution. The iron ions are intercalated into the interlayers of the GO sheets and also act as an effective initiator for pyrrole polymerization. ${ }^{15,26}$ As a result of this, the pyrrole is first oxidized to form a charged intermediate attached to the PLA filament. When additional $\mathrm{FeCl}_{3}$ solution is added dropwise, the charged pyrrole is more easily bound to the charged pyrrole which is already attached to the PLA. Thus, a high loading of PPy can be achieved. As a result, iron ions intercalated with GO composited with PPy as an active material grown onto the PLA filament (FGPP). The mass percentage of PPy is improved from $53 \%$ to $72.4 \%$ after introducing the iron ions, and the active material loading is $0.121 \mathrm{mg} \mathrm{cm} \mathrm{cm}^{-1}$. Furthermore, the resultant FGPP yarns are assembled into a flexible fiber-shaped supercapacitor with a high specific capacitance of $158.8 \mathrm{mF} \mathrm{cm}^{-2}$ and an energy density of $3.5 \mu \mathrm{W} \mathrm{h} \mathrm{cm}{ }^{-2}$. In addition, the resulting fibershaped supercapacitor retains the strength of the original yarn and its high flexibility, which shows a great potential for wearable electronics.

\section{Experimental section}

\subsection{Materials}

A commercial PLA filament with a density of $0.83 \mathrm{~g} \mathrm{~cm}^{-3}$, a cross-sectional area of $2.00 \times 10^{-4} \mathrm{~cm}^{2}$ and a fineness of 150
$\mathrm{D} / 75 \mathrm{f}$ was purchased from Zhejiang Xuri Fiber Co. Ltd. The PLA fiber was selected as the substrate because it is non-toxic, biodegradable and possesses good mechanical properties. The pyrrole monomer, anthraquinone-2-sulfonic acid (AQSA) and $\mathrm{FeCl}_{3} \cdot 6 \mathrm{H}_{2} \mathrm{O}$ were purchased from Sinopharm Chemical Reagent Co., Ltd. The GO was prepared using the chemical oxidation of natural graphite powder using the modified Hummer's method. ${ }^{27}$

\subsection{Intercalation of $\mathrm{FeCl}_{3}$ into GO}

The GO was mixed ultrasonically for $1 \mathrm{~h}$ at room temperature to form a stable suspension with a concentration of $2 \mathrm{mg} \mathrm{mL} \mathrm{mL}^{-1}$. Then the $\mathrm{FeCl}_{3}$ was added to the GO solution. The mass ratios of GO to $\mathrm{FeCl}_{3}$ were: $6: 0,6: 1,6: 2,6: 6$ (GO, FG-1, FG-2, FG-3), respectively. Afterwards, the mixtures were stirred for $30 \mathrm{~min}$ and then mixed ultrasonically for another $30 \mathrm{~min}$ at room temperature.

\subsection{Preparation of $\mathrm{GO}_{\mathrm{FeCl}_{3}}$ /PPy@PLA composite fibers}

The preparation of the $\mathrm{GO}_{\mathrm{FeCl}_{3}} / \mathrm{PPy} @ P L A$ (FGPP) composite fibers is shown schematically in Fig. 1. Firstly, the PLA filaments were rinsed sequentially with acetone and de-ionized water to remove any impurities. Then the filaments were dipped into solutions of mixtures of GO with $\mathrm{FeCl}_{3}$ (FG) for $5 \mathrm{~min}$, and this dipping operation was repeated to design various FG loads. Next, the filaments were dried at $80^{\circ} \mathrm{C}$, resulting in $\mathrm{GO}_{\mathrm{FeCl}_{3}}$ @PLA (FGP) filaments. As a control sample, GO@PLA (GP) filaments were obtained without using $\mathrm{FeCl}_{3}$. Secondly, PPy was deposited onto the FGP or GP filaments using in situ chemical polymerization. The filaments were immersed in an aqueous solution with AQSA $(0.01 \mathrm{M})$ and pyrrole $(0.12 \mathrm{M})$ at $0{ }^{\circ} \mathrm{C}$ for $2 \mathrm{~h}$. This causes the pyrrole to first be oxidized to form a charged intermediate attached to the PLA filament. When additional $\mathrm{FeCl}_{3}$ solution is added dropwise, the charged pyrrole is more easily bound to the charged pyrrole which is attached to the PLA. The AQSA dopant is able to strongly interact with the PPy main chain. ${ }^{28}$ Then an $\mathrm{FeCl}_{3}$ aqueous solution $(0.18 \mathrm{M})$ was added dropwise to initiate polymerization. The polymerization reaction lasted for $2 \mathrm{~h}$ at $0{ }^{\circ} \mathrm{C}$. Finally, the PPy-coated filaments were

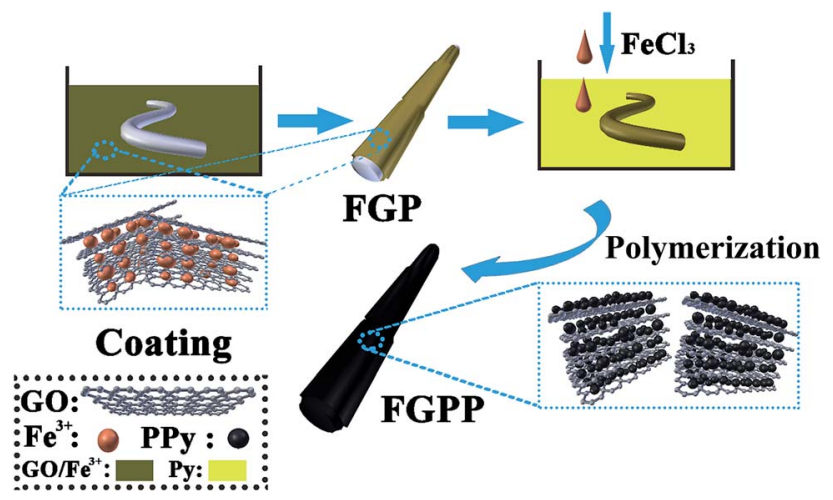

Fig. 1 Schematic diagram of the preparation of the FGPP electrode. 
obtained after washing with water to remove impurities and then dried in an oven at $100{ }^{\circ} \mathrm{C}$. The FGPP composite fibers with different mass ratios of $\mathrm{GO}$ and $\mathrm{FeCl}_{3}$ were labeled as GPP, FGPP-1, FGPP-2, FGPP-3.

\subsection{Characterization}

The X-ray diffraction (XRD) pattern was obtained using a diffractometer (D/Max-2250 PC, Rigaku, Japan) with $\mathrm{Cu} \mathrm{K} \alpha$ radiation, operated at $200 \mathrm{~mA}$ and $40 \mathrm{kV}$. The Fourier-transform infrared spectra (FTIR) was recorded using a spectrometer (Nicolet 6700, Thermo Electron Scientific Instruments Co. Ltd., USA) and X-ray photoelectron spectroscopy (XPS, Escalab 250, ThermoScientific, USA). The surface morphologies of the filaments were characterized using scanning electron microscopy (SEM, TM3000, Hitachi, Japan). The tensile properties of the FGPP and PLA were tested in a yarn tester (YG061FQ, Laizhou Electron Instrument Co., Ltd). The electrochemical measurements were carried out using a three-electrode and a twoelectrode test cell on a CHI 660D electrochemical workstation (CH Instruments) at room temperature. For the three-electrode test, the counter electrode was platinum and the reference electrode was silver/silver chloride $(\mathrm{Ag} / \mathrm{AgCl}) .{ }^{29}$ The electrolyte was an aqueous solution of $1 \mathrm{~mol} \mathrm{~L}^{-1}$ sodium chloride $(\mathrm{NaCl})$. The voltage window ranged was 0 to $0.8 \mathrm{~V}$, and the current densities varied from $125 \mathrm{~mA} \mathrm{~cm}^{-3}$ to $1250 \mathrm{~mA} \mathrm{~cm}^{-3}$. For the two-electrode test system, a gel electrolyte was used. To prepare the gel electrolyte, water $(10 \mathrm{~mL})$ and phosphoric acid $(10 \mathrm{~mL})$ were mixed and stirred for $30 \mathrm{~min}$. The poly(vinyl alcohol) (PVA) powder $(10 \mathrm{~g})$ was dissolved in $90 \mathrm{~mL}$ of water at $90{ }^{\circ} \mathrm{C}$ and then added to the above solution with stirring for $1 \mathrm{~h}$, followed by cooling down to room temperature. ${ }^{30}$ According to a previous report on a fiber supercapacitor, the areal specific capacitance $\left(C_{\mathrm{s}}\right)$, areal energy density $\left(E_{\mathrm{s}}\right)$ and areal power density $\left(P_{\mathrm{s}}\right)$ of supercapacitor were calculated using the following equations: ${ }^{\mathbf{2 0}}$

$$
\begin{gathered}
C_{\mathrm{s}}=(I \times \Delta t) /(S \times \Delta U) \\
E_{\mathrm{s}}=\left(C_{\mathrm{s}} \times \Delta U^{2}\right) / 7200 \\
P_{\mathrm{s}}=\left(E_{\mathrm{s}} \times 3600\right) / \Delta t
\end{gathered}
$$

Where $I(\mathrm{~A})$ is the current, $\Delta t(\mathrm{~s})$ is the discharge time, $\Delta U(\mathrm{~V})$ is the potential range of discharge, $S\left(\mathrm{~cm}^{2}\right)$ is the working area of the two electrodes excluding electrolyte, $C_{\mathrm{s}}\left(\mathrm{mF} \mathrm{cm}^{-2}\right)$ is the areal specific capacitance, $E_{\mathrm{s}}\left(\mathrm{mW} \mathrm{h} \mathrm{cm}^{-2}\right)$ is the areal energy density and $P_{\mathrm{S}}\left(\mathrm{mW} \mathrm{cm} \mathrm{cm}^{-2}\right)$ is the areal power density. For the assembly of symmetrical supercapacitors, the relationship between specific capacitance of the electrode and the device can be derived from the formula:

$$
\begin{gathered}
C_{\mathrm{s}, \text { device }}=\frac{C_{\text {device }}}{2 S_{\text {fibre }}} \\
C_{\mathrm{s}, \text { electrode }}=\frac{C_{\text {electrode }}}{S_{\text {fibre }}}=2 \frac{C_{\text {electrode }}}{S_{\text {fibre }}}=4 C_{\mathrm{s}, \text { device }}
\end{gathered}
$$

\section{Results and discussion}

\subsection{Structure of the intercalation of $\mathrm{GO}$ with $\mathrm{FeCl}_{3}$}

The XRD patterns of the $\mathrm{FeCl}_{3}$-modified GO sheets are shown in Fig. 2. Because of the oxygenated functional groups, the interlayer spacing of the GO sheets obtained from the (001) peak was approximately $0.826 \mathrm{~nm}\left(2 \theta=10.3^{\circ}\right)$, which was larger than that of graphite $(0.34 \mathrm{~nm}) .{ }^{31}$ By increasing the mass ratio of the $\mathrm{FeCl}_{3}$, the intensity of the peak at $10.3^{\circ}$ was significantly reduced and the interlayer spacing of the intercalated complex was gradually increased (Fig. S1, ESI $\dagger$ ). This phenomenon indicated that $\mathrm{FeCl}_{3}$ enlarged the sheet distance of the GO layer and destroyed the orderly arrangement of the GO sheets. For the mass ratio of $\mathrm{FeCl}_{3}$ to $\mathrm{GO}$ of $6: 6$, the peak at $10.3^{\circ}$ disappeared completely. So, according to the results of previous work, $\mathrm{FeCl}_{3}$ can achieve intercalation of the GO sheets to form a stable mixture. $^{32}$

The effective intercalation of $\mathrm{FeCl}_{3}$ into the $\mathrm{GO}$ layers was further verified from the FTIR results (Fig. S2, ESI $\dagger$ ). The peak at $3433 \mathrm{~cm}^{-1}$ assigned to the $\mathrm{O}-\mathrm{H}$ groups ${ }^{33}$ between the GO sheets was downshifted after $\mathrm{FeCl}_{3}$ was added to GO. For the plain GO solution, the peaks at 1630,1400 and $1061 \mathrm{~cm}^{-1}$ were attributed to the $\mathrm{C}=\mathrm{C}$ groups, ${ }^{34}$ the $\mathrm{C}-\mathrm{OH}$ groups ${ }^{35}$ and the $\mathrm{C}-\mathrm{O}$ groups, ${ }^{36}$ respectively. After the intercalation of $\mathrm{FeCl}_{3}$, the intensities of the characteristic peaks were reduced, which was thought to be because of the positive charges of the $\mathrm{Fe}^{3+}$ ions which could bind the negative charges in GO. It was confirmed that the $\mathrm{FeCl}_{3}$ had been successfully intercalated within the GO layers. The Raman spectra of the PLA filaments, GO, FGP and FGPP are shown in Fig. S3 (ESI). $\dagger$ The typical D $\left(1350 \mathrm{~cm}^{-1}\right)$ and $G$ $\left(1580 \mathrm{~cm}^{-1}\right.$ ) bands for the crystalline graphitic carbon were observed for GO. After the intercalation of $\mathrm{FeCl}_{3}$ into GO, the D peak was broadened, indicating that the GO structure layer was disturbed, which agreed with the XRD results. ${ }^{37}$ The FGPP, peaks around $1065 \mathrm{~cm}^{-1}$ and $968 \mathrm{~cm}^{-1}$ were related to the inplane and out-of-plane vibrations of the $\mathrm{N}-\mathrm{H}$, and $\mathrm{C}-\mathrm{H}$ modes, respectively, which implied that the PPy had grown on the surface of the FGP. ${ }^{38}$ Furthermore, the XPS spectrum of FGPP is shown in Fig. S4 (ESI), $\uparrow$ from which only oxygen (O), C

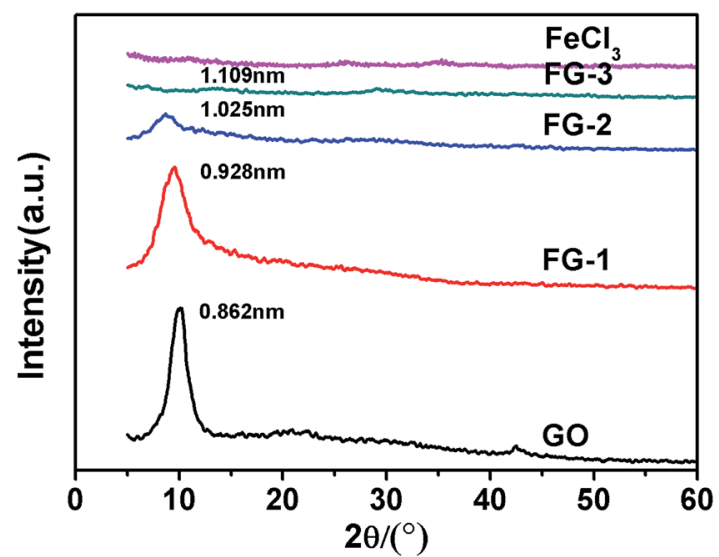

Fig. 2 The XRD patterns of the intercalation of GO with different mass ratios of $\mathrm{FeCl}_{3}$. 
and $\mathrm{N}$ elements were detected..$^{22}$ However, the PLA fiber did not contain elemental $\mathrm{N}$, which was partly because of the PPy deposition.

\subsection{The morphology of the FGPP fibers}

In situ chemical polymerization of pyrrole (Py) was conducted to prepare an FGPP fiber. The bare PLA filaments were clean and smooth (Fig. 3a). After dipping in the GO and FG solutions, the PLA filaments were fully covered with a layer of GO (Fig. 3b) and FG (Fig. 3c) film, respectively. The FG was coated uniformly on the surface of the PLA fibers (Fig. S5a, ESI $\dagger$ ). It can be seen that some PPy particles were attached to the surface of the FGP
(Fig. 3d) after just throwing the FGP filaments into the Py monomer solution without initiators, which confirmed the presence of $\mathrm{Fe}^{3+}$ ions on the surface of filaments. However, the PPy particles were unevenly distributed and there were very few on the filaments because the amount of $\mathrm{Fe}^{3+}$ ions was not enough to generate further polymerization. As a result, the initiation of the polymerization could not entirely rely on the adsorbed $\mathrm{Fe}^{3+}$ ions. Only some small PPy particles were formed, but these particles can provide a place for subsequent pyrrole polymerization. When additional $\mathrm{Fe}^{3+}$ ions were added to the Py solution, Py was oxidized to form a charged free radical. These PPy particles were more likely to trap charged Py molecules. Therefore, more PPy can be formed on the fibers. A comparison
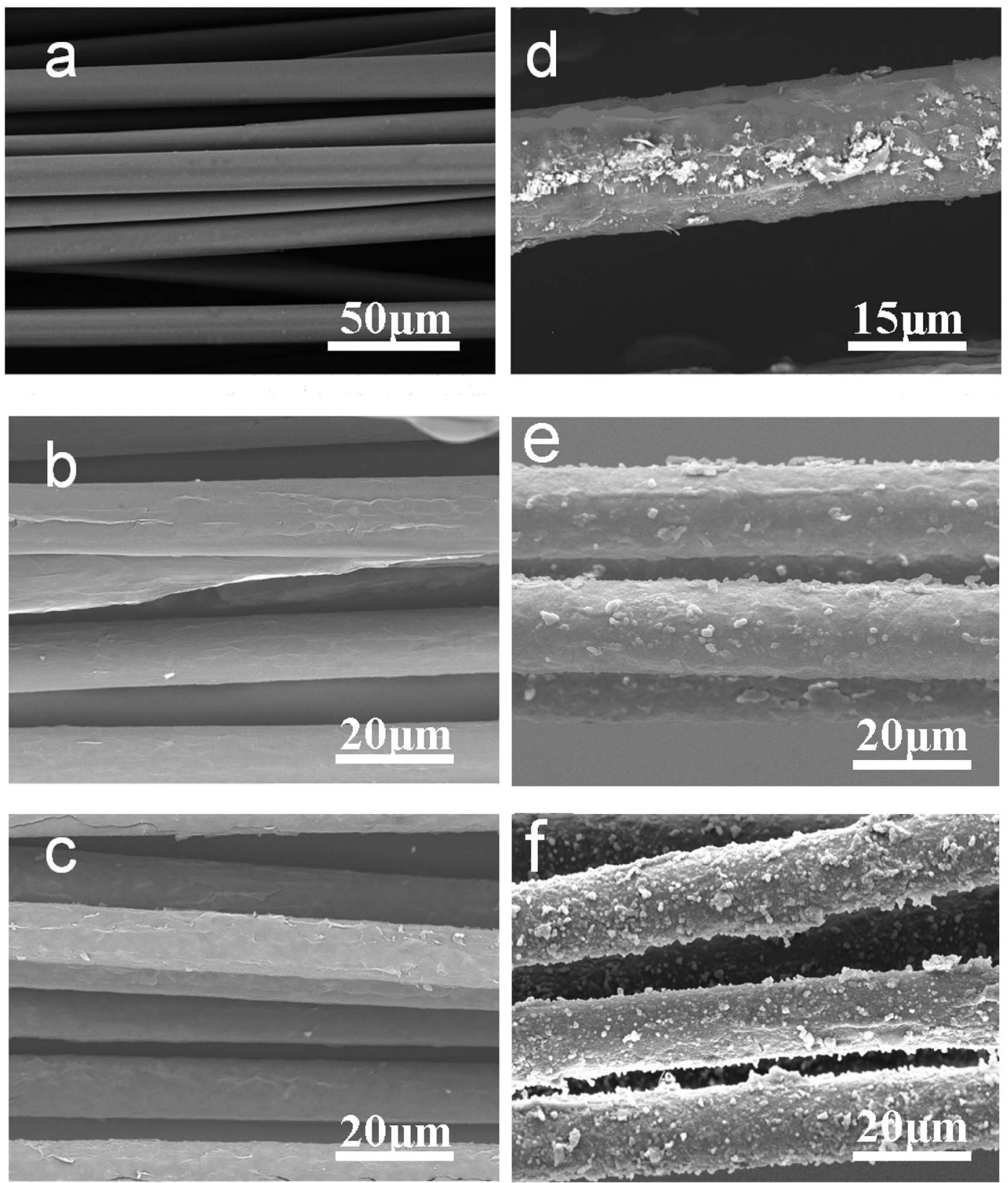

Fig. 3 (a) PLA filaments, (b) GP filaments, (c) FGP filaments, (d) the FGPP filaments which were set into the pyrrole without other initiators, (e) GPP filaments, and (f) FGPP filaments when the mass ratio of $\mathrm{GO}: \mathrm{FeCl}_{3}$ is $6: 6$. 
was made of the morphology of the GPP and FGPP filaments (Fig. 3e and f). It was observed that the mass loading of PPy attached to the filament's surface was markedly increased after the intercalation of $\mathrm{FeCl}_{3}$. Furthermore, the PPy coating was uniform and well-bonded (Fig. S5b, ESI $\dagger$ ). This phenomenon was attributed to the $\pi-\pi$ conjugation and hydrogen bonding between PPy and GO, but also the $\mathrm{FeCl}_{3}$ absorbed inside the filaments. Therefore, the presence of $\mathrm{FeCl}_{3}$ was vital for the PPy polymerization. The mass ratios of $\mathrm{FeCl}_{3}$ to $\mathrm{GO}$ also play a critical role in the subsequent polymerization. The PPy mass loading was increased with the increasing mass ratio up to $6: 6$. The weight percentage of PPy was improved from 53\% to $72.4 \%$ (Fig. S6, ESI $\dagger$ ). As was demonstrated, the best performance of the conductive polymers was reached the when the loadings reached $70 \% .^{39}$ Therefore, increasing the mass loading of PPy could effectively improve the performance of the fiber-shaped supercapacitors.

\subsection{The mechanism of the intercalation of $\mathrm{FeCl}_{3}$ into GO sheets}

From the XRD results, it could be seen that the interlayer spacing of the GO sheets was $0.826 \mathrm{~nm}$. When $\mathrm{FeCl}_{3}$ was mixed with GO, the interlayer spacing of the GO sheets was enlarged to $1.109 \mathrm{~nm}$. It is known that the intercalation can be achieved by the reaction between the positive charges of $\mathrm{FeCl}_{3}$ and the negative charges of GO. The ionic radius of $\mathrm{Fe}^{3+}$ is $0.4 \mathrm{~nm}$. The XRD results show that the interlayer spacing of GO was increased by nearly $0.3 \mathrm{~nm}$, which indicated the successful insertion of $\mathrm{FeCl}_{3}$ into the GO layer. When the $\mathrm{FeCl}_{3}$-modified GO was coated onto the PLA surface, it was expected that the structure of the $\mathrm{FeCl}_{3}$-modified $\mathrm{GO}$ was maintained. For the polymerization of Py with $\mathrm{FeCl}_{3}$, its process agrees with the kinetics given by Bjorklund. ${ }^{25}$ The process of pyrrole (P) polymerization is described in the following equations:

$$
\begin{gathered}
\mathrm{P}+\mathrm{Fe}^{3+} \rightarrow \mathrm{P}^{+}+\mathrm{Fe}^{2+} \\
2 \mathrm{P}^{+} \rightarrow \mathrm{P}-\mathrm{P}+2 \mathrm{H}^{+} \\
\mathrm{P}-\mathrm{P}+\mathrm{Fe}^{3+} \rightarrow \mathrm{P}-\mathrm{P}^{+}+\mathrm{Fe}^{2+} \\
\mathrm{P}-\mathrm{P}^{+}+\mathrm{P}^{+} \rightarrow \mathrm{P}-\mathrm{P}-\mathrm{P}+2 \mathrm{H}^{+}
\end{gathered}
$$

Thus, by just throwing the FGP filaments into the Py monomer solution without initiators for $2 \mathrm{~h}$, Py was first oxidized to form a charged intermediate attached onto a PLA filament. When additional $\mathrm{FeCl}_{3}$ solution was added dropwise, the charged Py was more easily bound to the charged pyrrole which was attached to the PLA. Therefore, it was better to form a homogeneous hybrid active material in the presence of $\mathrm{FeCl}_{3}$ and the mass loading was also increased. The interaction between Py and FGP involved both physical and chemical processes. The PPy was grown on fibers using chemical polymerization of Py monomers using $\mathrm{Fe}^{3+}$ as oxidants, and this was a chemical process. Meanwhile, the Py monomers and GO were intercalated through the $\pi-\pi$ interaction and the electropositive and negative physical adsorption, which was a physical process. $^{40}$

\subsection{Electrical performance of FGPP fibers}

Before the characterization of the electrical properties, the tensile properties of the PLA and FGPP were tested in a yarn tester. Fig. S7 (ESI) $\dagger$ shows the results of the testing which showed that the modified PLA had a high tensile strength and the coating process did not damage the strength of the fibers.

The conductivity of the FGPP fibers was determined and the results are shown in Fig. 4. The addition of $\mathrm{FeCl}_{3}$ has an important influence on the conductivity. An increase in the conductivity was witnessed when the mass of the $\mathrm{FeCl}_{3}$ increased (Fig. 4a). In particular, the conductivity of the FGPP-3 fiber was $652 \mathrm{~S} \mathrm{~m}^{-1}$. The conductive stability of the FGPP-3 fiber is shown in Fig. 4b. The conductivity was almost stable when the composite fiber underwent bending $\left(180^{\circ}\right)$ and twisting $\left(90^{\circ}\right)$ deformations. More interestingly, using a simple sewing machine, the fiber could be woven into a pattern of "DHU" and a twill sample (Fig. 4c). In all cases, the fibers could effectively act as flexible conductor wires and have a high and stable conductivity (Fig. 4d). At the same time, the conductive fabric, which was obtained by weaving the FGPP fibers, had a low resistance value.

\subsection{Electrochemical performance of FGPP fibers}

To evaluate the electrochemical properties of the FGPP composite fibers, the electrochemical performance was measured using three-electrode and two-electrode measuring systems. Fig. 5a and b compares cyclic voltammograms (CV) and galvanostatic charge-discharge profiles (GCD) of the electrodes based on four different mass ratios of $\mathrm{FeCl}_{3}$ to $\mathrm{GO}$ in a three-electrode test system. From the CV curves (Fig. 5a), it can be seen that they share the same shape but with different areas, which indicated that there were similar redox reactions but different specific capacitances. Furthermore, all the composite electrodes exhibited a symmetrical and closely linear slope during charging and discharging processes (Fig. 5b), suggesting that there was a good supercapacitor electrode behavior. There was a potential difference (IR drop) in voltage during discharge which mainly originated from the electrolyte resistance, electrode resistance and charge transfer resistance $\left(R_{\mathrm{ct}}\right)$ of the entire devices. The IR drop was decreased with the increasing proportions of $\mathrm{FeCl}_{3}$ corresponding to the decreasing $R_{\mathrm{ct}}$. That is to say, the intercalated structure effectively improved the conductivity and reduced the overall resistance. The FGPP-3 displayed the highest electrochemical performance and was carefully investigated further. Fig. $5 \mathrm{c}$ shows the CV curves of the FGPP-3 composite electrode at various scan rates. It can be seen that the FGPP-3 electrode displayed relatively rectangular CV curves at a low scan rate $\left(5 \mathrm{mV} \mathrm{s}^{-1}\right)$. When the scanning rate was increased to $100 \mathrm{mV} \mathrm{s}^{-1}$, the curve still showed a slightly sloped rectangular-like shape within a potential window from $0-0.8 \mathrm{~V}$, which showed there was a high rate performance with efficient ionic and electronic transports. Fig. 5d shows the GCD of the FGPP-3 electrode at different current densities and all of the 

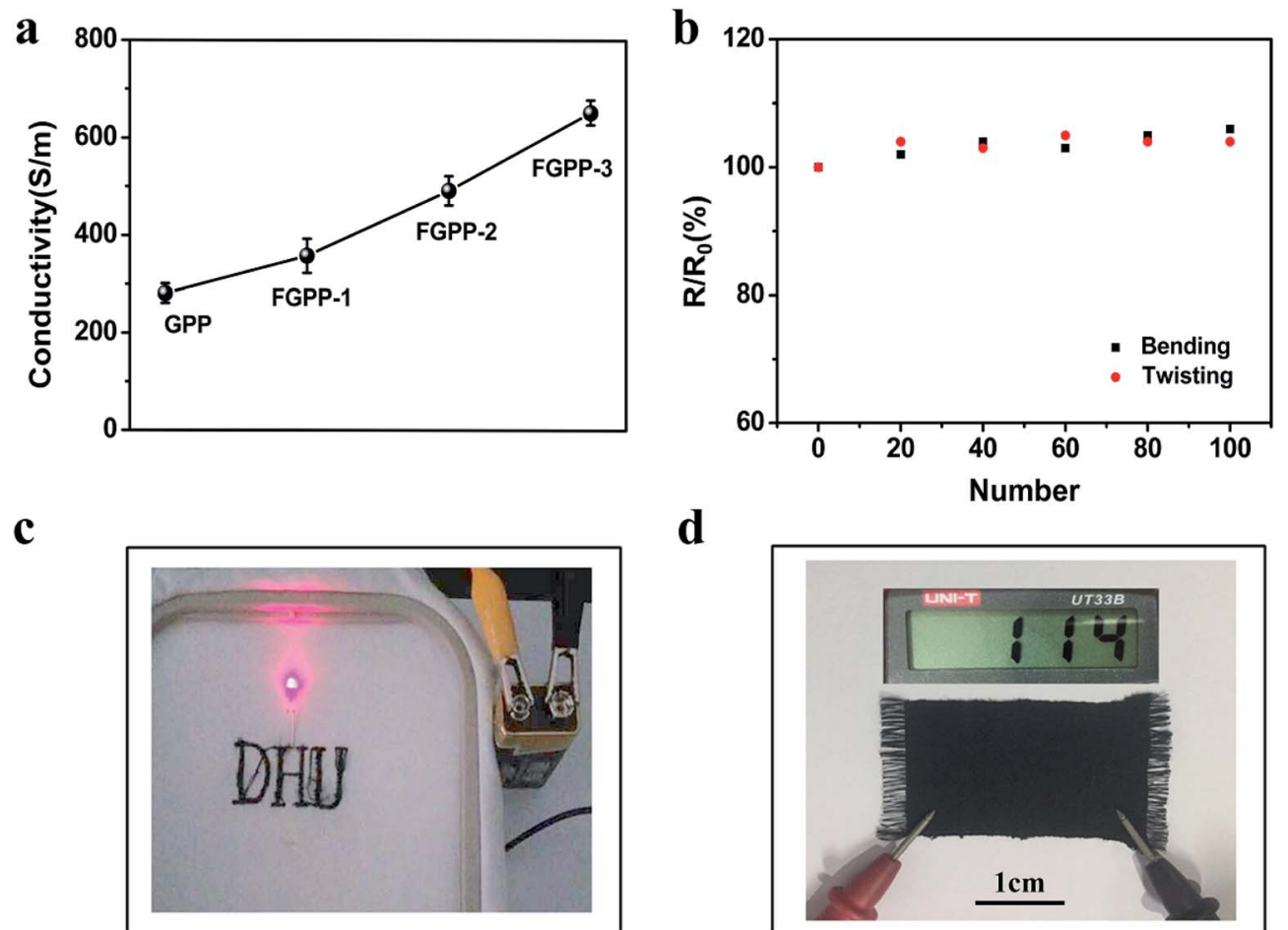

d

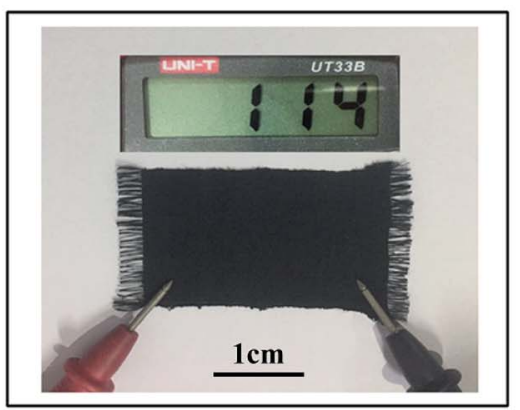

Fig. 4 (a) Effect of conductivity of the FGPP fiber on the mass of $\mathrm{FeCl}_{3}$. (b) Conductivity stability of the FGPP-3 fiber upon bending and twisting. (c) Digital images of embroidered logos of the word: DHU, using the composite electrode filaments to light up the LED. (d) The twill fabric made from the composite electrode filaments using the weaving machine.
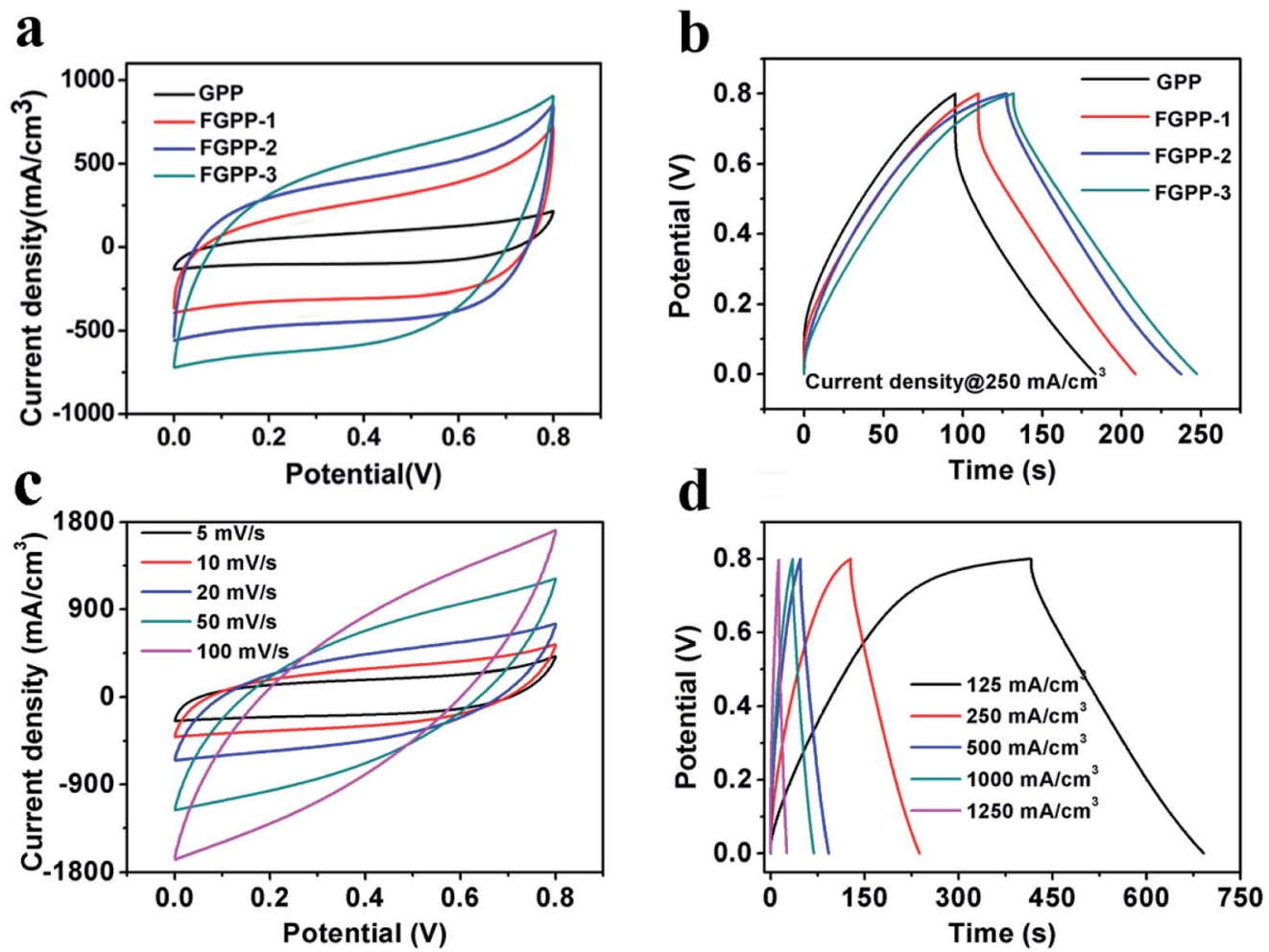

Fig. 5 (a) The CV curves of the FGPP-X electrode measured in $\mathrm{NaCl}$ electrolyte at a scan rate of $20 \mathrm{mV} \mathrm{s}^{-1}$, (b) the GCD of the FGPP-X electrode measured in $\mathrm{NaCl}$ electrolyte at a current density of $250 \mathrm{~mA} \mathrm{~cm}^{-3}$, (c) the CV curves of FGPP-3 measured in $\mathrm{NaCl}$ electrolyte with scan rates ranging from $5 \mathrm{mV} \mathrm{s}^{-1}$ to $100 \mathrm{mV} \mathrm{s}^{-1}$, (d) the GCD of FGPP-3 measured in NaCl electrolyte with current densities from $125 \mathrm{~mA} \mathrm{~cm}{ }^{-3}$ to $1250 \mathrm{~mA}$ $\mathrm{cm}^{-3}$. 
curves exhibit triangular shapes. At a low current density (125 $\mathrm{mA} \mathrm{cm}{ }^{-3}$ ), some side reactions will occur in the electrochemical redox reaction, resulting in slow charging at a high potential. As the current density increased, the charge and discharge time decreased, and the electrochemical process was mainly affected by the double-layer structure, and the coulomb efficiency increases. In particular, the coulombic efficiency can be kept at $95 \%$ even if the current density was as high as $250 \mathrm{~mA} \mathrm{~cm} \mathrm{~cm}^{-3}$, which verified the excellent reversibility of the electrode.

The FGPP-3 filaments were further assembled into a flexible fiber shaped supercapacitor. Two FGPP-3 filaments with a length of $3 \mathrm{~cm}$ were coated with a gel electrolyte and then arranged in parallel to form a supercapacitor. The GPP electrodes were also fabricated into fiber shaped supercapacitors. Fig. 6a shows the CV curves of two of the supercapacitors at a scan rate $5 \mathrm{mV} \mathrm{s}^{-1}$. It was obvious that the $\mathrm{CV}$ area of the FGPP-3-based device was much larger than that of the GPPbased device. The GCD curves, at a current density of $33 \mathrm{~mA}$ $\mathrm{cm}^{-3}$, of the solid-state supercapacitors are shown in Fig. $6 \mathrm{~b}$. The IR drop of the FGPP-3-based device was small and the GCD curve demonstrated a nearly symmetrical triangular shape, which implied excellent electrochemical capacitive behavior. All

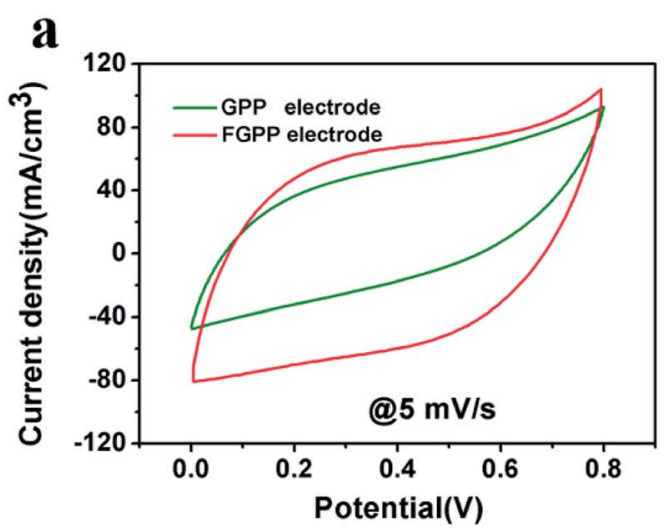

b
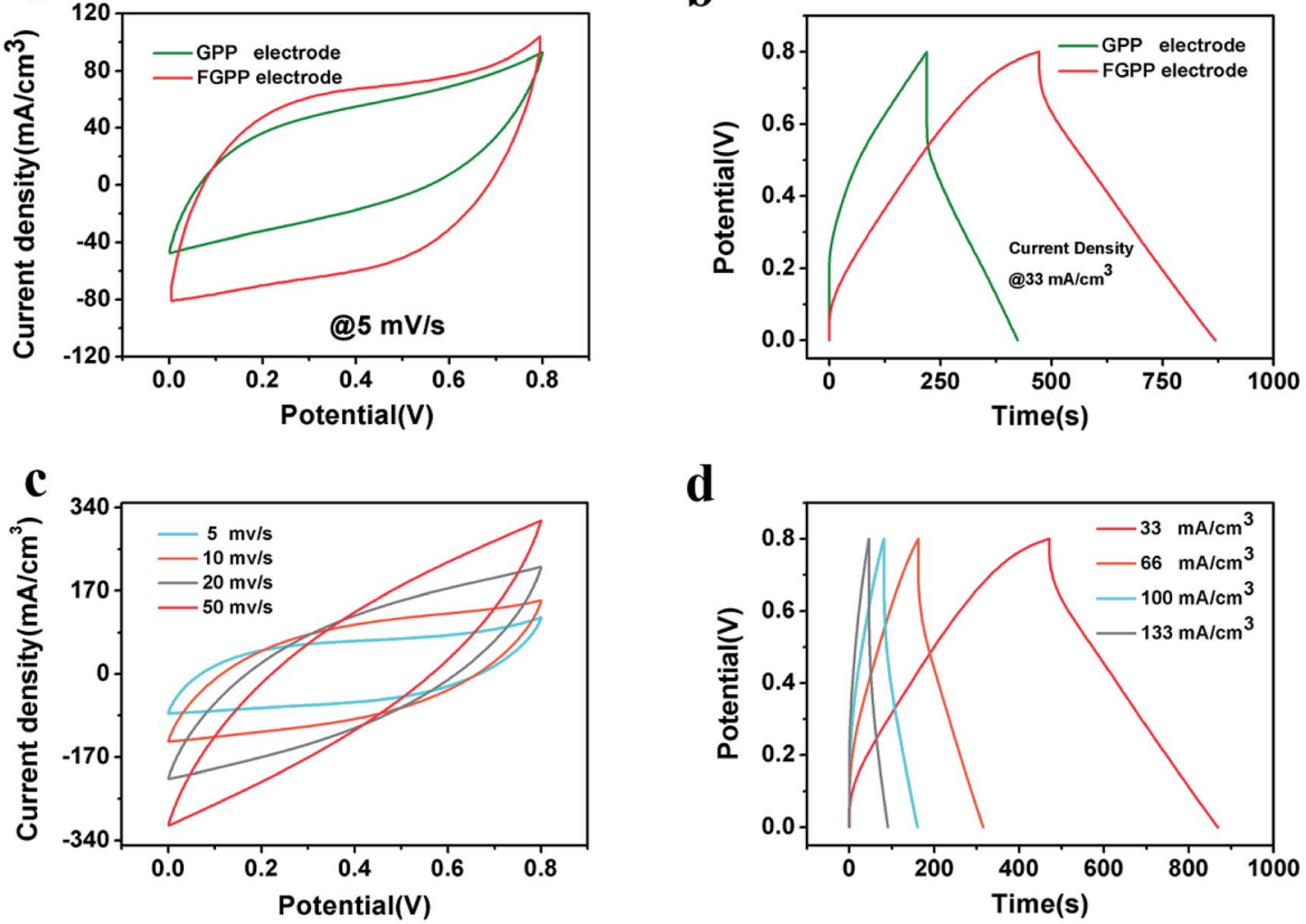

d
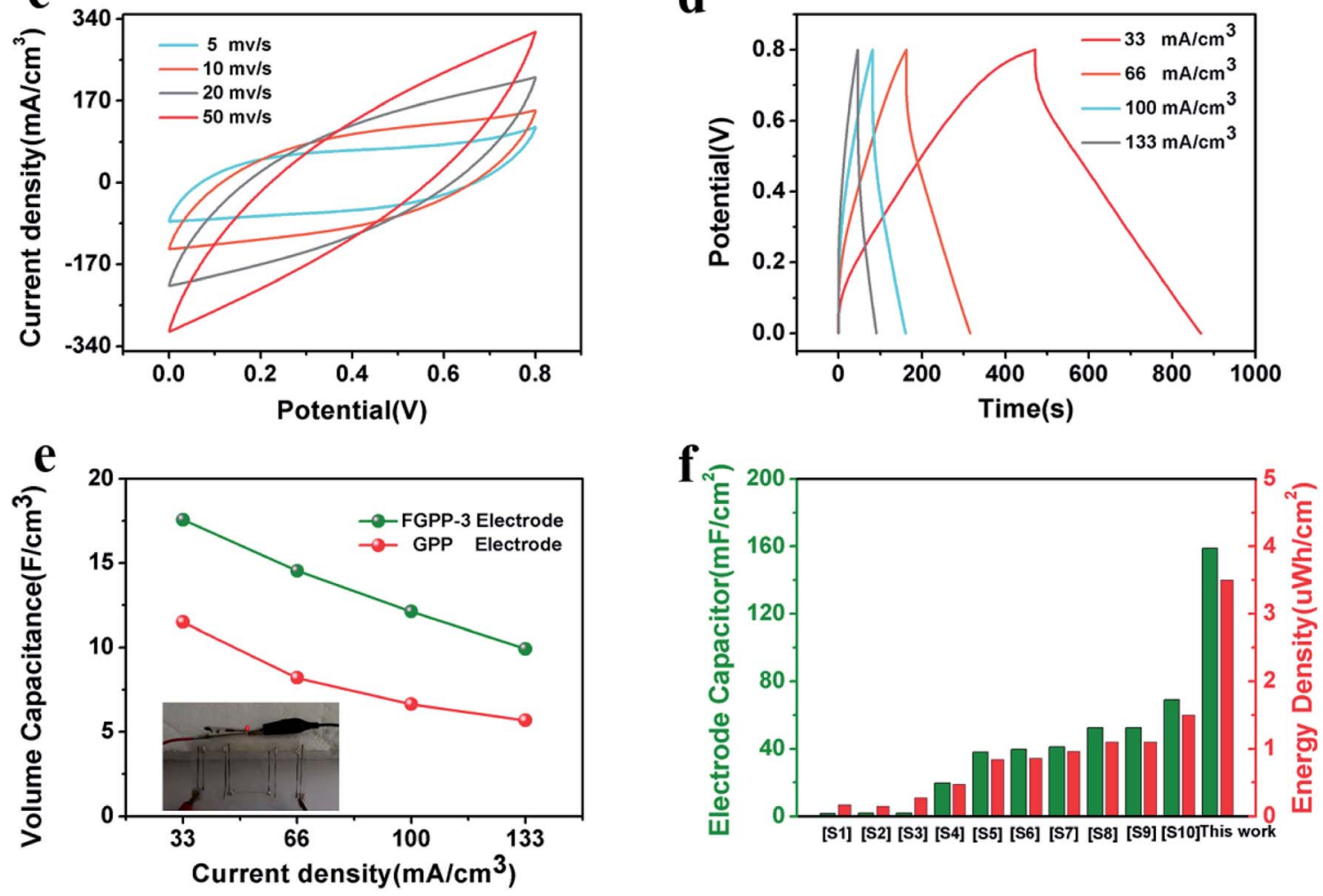

Fig. 6 (a) The CV curves of FGPP-3 and GPP solid supercapacitors at the scan rate of $5 \mathrm{mV} \mathrm{s}^{-1}$, (b) the GCD curves of FGPP-3 and GPP solid supercapacitors with a current density of $33 \mathrm{~mA} \mathrm{~cm}{ }^{-3}$, (c) the CV curves of the FGPP-3 device at different scan rates, (d) the GCD curves at different current densities of the FGPP-3 device, (e) the different current densities corresponding to the areal specific capacitance of the FGPP-3 and GPP devices, (f) a comparison of the electrochemical performances obtained in this research with other fiber-shaped supercapacitors using areal specific capacitance $\left(C_{\mathrm{s}}\right)$, and areal energy density $\left(E_{\mathrm{s}}\right)$. 

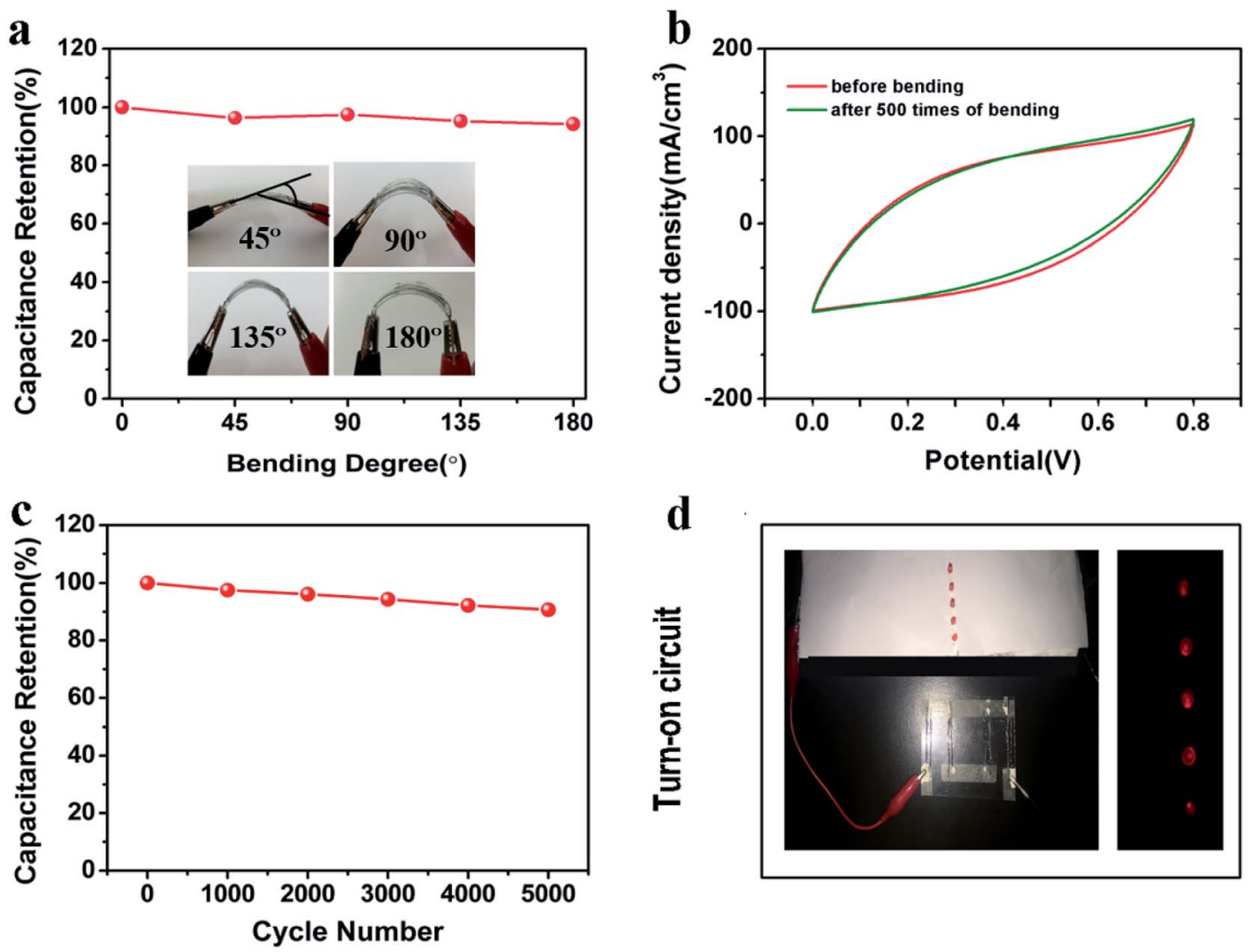

Fig. 7 (a) Capacitance retention of the device under different bending states. (b) CV curves of the device before and after bending 500 times. (c) Cycle life of the fiber-shaped supercapacitor. (d) Photographs of four supercapacitors before and after connection to power five LEDs. The supercapacitors all had a length of $3.0 \mathrm{~cm}$ and were connected in series.

of these results proved that the absorbed $\mathrm{FeCl}_{3}$ was beneficial for the improvement of the electrochemical properties. Fig. $6 \mathrm{c}$ and d show the CV curves and the GCD curves of a FGPP-3 fiber shaped supercapacitor at different scan rates and current densities, respectively. The CV curves displayed relatively rectangular $\mathrm{CV}$ curves at a relatively low scan rate $\left(5 \mathrm{mV} \mathrm{s}^{-1}\right)$, which indicated a nearly ideal supercapacitor behavior (Fig. 6c). The GCD at different current densities exhibited triangular shapes with a coulombic efficiency of $\sim 95 \%$ (Fig. $6 \mathrm{~d}$ ), and the areal specific capacitances $\left(C_{\mathrm{s}}\right)$ of FGPP-3 were $39.7\left(17.58 \mathrm{~F} \mathrm{~cm}^{-3}\right)$, $32.61,27.38$ and $22.4 \mathrm{mF} \mathrm{cm}^{-2}$ at $0.075,0.15,0.225$ and $0.3 \mathrm{~mA}$ $\mathrm{cm}^{-2}$, respectively, which were higher than those of the GPP, which were $26,18.51,14.98,12.79 \mathrm{mF} \mathrm{cm}^{-2}$ at the same current density (Fig. 6e). It is well known that the specific capacitance of each electrode (single electrode) was four times the total cell specific capacitance. According to the formula, the areal specific capacitance for each electrode of the cell used in this work was $158.8 \mathrm{mF} \mathrm{cm}^{-2}$. A common pseudocapacitance material is PPy, and with an increase of current density, the electrode surface reactants will rapidly decrease, the concentration polarization of the system will increase, and the incomplete chemical redox reaction will occur, which was reflected in the decrease of capacitance value with the increase of current density. ${ }^{40}$ The energy density of the supercapacitor assembled in this work was then calculated to be $3.5 \mu \mathrm{W} \mathrm{h} \mathrm{cm}{ }^{-2}\left(1.56 \mathrm{~mW} \mathrm{~h} \mathrm{~cm}^{-3}\right)$ and the

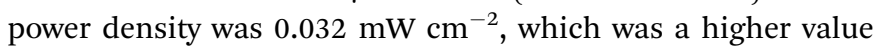

than those reported in some previous research [Fig. 6f, Table S1 (ESI)†].

The flexibility and stability of the resulting supercapacitor based on two FGPP-3 fibers was also explored. Significantly, the specific capacitances were almost unchanged under bending with a bending angle of $180^{\circ}$ (Fig. 7a), and the CV curves were almost overlapped before and after bending for 500 cycles (Fig. 7b). This means that this fiber supercapacitor has a superb stable capacitance with bending. Furthermore, the device showed an excellent long-life performance up to 5000 cycles with a retention of $\sim 90.7 \%$ (Fig. $7 \mathrm{c}$ ). For the XRD spectrum (Fig. S8, ESI $\dagger$ ), the diffraction peaks around $16^{\circ}$ and $21^{\circ}$ were attributed to PPy ${ }^{41}$ and the PVA electrolyte. ${ }^{42}$ There was little change before and after the cycle as shown in the XRD patterns of FGPP with electrolyte, which implied that the PPy did not collapse after the cycle. As a demonstration of energy storage, the fiber-shaped supercapacitors can be readily connected in series to provide a high power output, e.g., four FGPP-based supercapacitors were connected to power five light-emitting diodes (LEDs) (Fig. 7d).

\section{Conclusions}

In summary, in order to improve the capacitance and energy density of fiber-shaped electrodes, GO sheets were modified by intercalation with $\mathrm{FeCl}_{3}$. The mass ratio of $\mathrm{FeCl}_{3}$ to $\mathrm{GO}$ had 
a great effect on the loading capability of the active material (PPy) and the subsequent electrochemical properties. The optimal fiber-shaped supercapacitor with a mass ratio of $6: 6$ produced a high mass loading of PPy and a high areal specific capacitance of $158.8 \mathrm{mF} \mathrm{cm}^{-2}$. The energy density of the assembled supercapacitor was $3.5 \mu \mathrm{W} \mathrm{h} \mathrm{cm}{ }^{-2}$ at a power density of $0.032 \mathrm{~mW} \mathrm{~cm}^{-2}$, which was much higher than those results found in other reports. This fiber-shaped supercapacitor was flexible and performed stably under bending deformation, which rendered it promising for use in many emerging fields such as portable and wearable electronics.

\section{Conflicts of interest}

The authors declare that they have no conflicts of interest.

\section{Acknowledgements}

This work is supported by the Fundamental Research Funds for the Central Universities (2232018G-02).

\section{References}

1 W. Liu, M. S. Song, B. Kong and Y. Cui, Adv. Mater., 2017, 29, 1603436.

2 R. Raccichini, A. Varzi, S. Passerini and B. Scrosati, Nat. Mater., 2015, 14, 271-279.

3 X. Chen, H. Lin, J. Deng, Y. Zhang, X. Sun, et al., Adv. Mater., 2014, 26, 8126-8132.

4 Y. Wang, Z. Shi, Y. Huang, Y. Ma, C. Wang, et al., J. Phys. Chem. C, 2009, 113, 13103-13107.

5 Z. Y. Zhou, Q. C. Zhang, J. Sun, B. He, J. B. Guo, Q. L. Li, C. W. Li, L. Y. Xie and Y. G. Yao, ACS Nano, 2018, 12, 93339341.

6 S. Wang, N. Liu, J. Su, L. Li, F. Long, et al., ACS Nano, 2017, 5, 2066-2074.

7 M. Li, M. Zu, J. Yu, H. Cheng and Q. Li, Small, 2017, 13, 1602994.

8 X. Jiang, D. Jianning, Z. Xiaoshuang, Z. Yang and Z. Wenjun, J. Power Sources, 2017, 340, 302-308.

9 Q. C. Zhang, W. W. Xu, J. Sun, Z. H. Pan, J. X. Zhao, X. N. Wang, J. Zhang, P. Man, J. B. Guo, Z. Y. Zhou, B. He, Z. X. Zhang, Q. W. Li, Y. G. Zhang, L. Xu and Y. G. Yao, Nano Lett., 2017, 17, 7552-7560.

10 J. X. Zhao, Y. Zhang, Y. N. Huang, J. X. Xie, X. X. Zhao, C. W. Li, J. Y. Qu, Q. C. Zhang, J. Sun, B. He, Q. L. Li, C. H. Lu, X. H. Xu, W. B. Lu, L. Q. Li and Y. G. Yao, Adv. Sci., 2018, 5, 1801114.

11 Z. Y. Li, M. S. Akhtar and O. B. Yang, J. Alloys Compd., 2015, 653, 212-218.

12 Q. Li, N. Mahmood, J. Zhu, Y. Hou and S. Sun, Nano Today, 2014, 9, 668-683.

13 T. G. Yun, B. Hwang, D. Kim, S. Hyun and S. M. Han, ACS Appl. Mater. Interfaces, 2015, 7, 9228-9234.

14 X. B. Zang, X. Li, M. Zhu, X. M. Li, Z. Zhen, et al., Nanoscale, 2015, 7, 7318-7322.
15 Y. Zhu, K. Shi and I. Zhitomirsky, J. Power Sources, 2014, 268, 233-239.

16 Q. H. Meng, K. Wang, W. Guo, J. Fang, et al., Small, 2014, 10, 3187-3193.

17 G. X. Qu, J. L. Cheng, X. D. Li, D. M. Yuan, et al., Adv. Mater., 2016, 28, 3646-3652.

18 L. M. Liu, W. Weng, X. Y. Dai, N. Liu, et al., RSC Adv., 2016, 6, 108362-108368.

19 L. B. Liu, Y. Yu, C. Yan, K. Li, et al., Nat. Commun., 2015, 6, 9. 20 J. Xu, D. X. Wang, Y. Yuan, W. Wei, L. L. Duan, et al., Org. Electron., 2015, 24, 153-159.

21 E. Mitchell, J. Candler, F. De Souza, R. K. Gupta, B. K. Gupta and L. F. Dong, Synth. Met., 2015, 199, 214-218.

22 S. Y. Lyu, H. J. Chang, F. Fu, L. Hu, J. D. Huang and S. Q. Wang, J. Power Sources, 2016, 327, 438-446.

23 Z. Zhang, J. Deng, X. Li, Z. Yang, S. He, et al., Adv. Mater., 2015, 27, 356-362.

24 X. F. Gong, S. H. Li and P. S. Lee, Nanoscale, 2017, 9, 1079410801.

25 R. B. Bjorklund, J. Chem. Soc., Faraday Trans., 1987, 83, 15071514.

26 Y. Huang, H. F. Li, Z. F. Wang, M. S. Zhu, Z. X. Pei, et al., Nano Energy, 2016, 22, 422-438.

27 D. C. Marcano, D. V. Kosynkin, J. M. Berlin, A. Sinitskii, Z. Sun, et al., ACS Nano, 2010, 4, 4806.

28 S. H. Kim, S. H. Jang, S. H. Yun, J. Y. Lee, et al., J. Appl. Polym. Sci., 2013, 12, 1969-1974.

29 L. B. Liu, Y. Yu, C. Yan, K. Li and Z. J. Zheng, Nat. Commun., 2015, 6, 9.

30 S. Jiang, T. Shi, X. Zhan, H. Long, S. Xi, et al., J. Power Sources, 2014, 272, 16-23.

31 Z. J. Fan, W. Kai, J. Yan, T. Wei, L. J. Zhi, et al., ACS Nano, 2011, 5, 191-198.

32 D. Zhan, L. Sun, Z. H. Ni, L. Liu, X. F. Fan, et al., Adv. Funct. Mater., 2010, 20, 3504-3509.

33 P. Y. Tang, L. J. Han and L. Zhang, ACS Appl. Mater. Interfaces, 2014, 6, 10506-10515.

34 K. B. Yin, H. T. Li, Y. D. Xia, H. C. Bi, J. Sun, et al., Nano-Micro Lett., 2011, 3, 51-55.

35 C. Bao, L. Song, W. Xing, B. Yuan, C. A. Wilkie, et al., J. Mater. Chem., 2012, 22, 6088-6096.

36 T. A. Pham, B. C. Choi and Y. T. Jeong, Nanotechnology, 2010, 21, 10.

37 Z. M. Gu, C. Z. Li, G. C. Wang, L. Zhang and X. H. Li, J. Polym. Sci., Part B: Polym. Phys., 2010, 48, 1329-1335.

38 S. Y. Lyu, H. J. Chang, F. Fu, L. Hu, J. D. Huang and S. Q. Wang, J. Power Sources, 2016, 327, 438-446.

39 H. Sun, X. Fu, S. Xie, Y. Jiang and H. Peng, Adv. Mater., 2016, 28, 2070-2076.

40 C. Q. Lin, B. N. Popov and H. J. Ploehn, J. Electrochem. Soc., 2002, 149, 167-175.

41 J. Hu, M. Li, F. Lv, M. Yang, P. Tao, Y. Tang, H. Liu and Z. Lu, J. Power Sources, 2015, 294, 120-127.

42 G. K. Prajapati, R. Roshan and P. N. Gupta, J. Phys. Chem. Solids, 2010, 71, 1717-1723. 